\title{
Intraoperative Aortic Dissection Complicating Elective Off-pump Coronary Artery Bypass Surgery
}

\author{
Abdusalom A. Abdurakhmanov
}

1) Department of Cardiac Surgery, Republican Research Center of Emergency Medicine, Tashkent, Uzbekistan

\begin{abstract}
Aim: We conducted this study to identify current trends and risk factors for iatrogenic dissection.

Methods: From December 2013 to November 2017 in Republican Research Center for Emergency Medicine, 711 patients (mean age 54+/-2,3 years old) were operated electively. Off-pump coronary artery bypass grafting procedures was performed in all cases. Patients' preoperative risk factors, and operative and postoperative courses were analyzed from the hospital records retrospectively.

Results: Of the 711 patients, who had off-pump coronary artery bypass, $2(0.28 \%)$ developed iatrogenic intraoperative aortic dissection. Patients with the iatrogenic aortic dissection were in older age group (62 and 68 years old). Both patients had dissection extending beyond the aortic arch. IAAD was identified after removing the side clamp from the aorta in both patients; however, the intimal tear was located on the site of proximal anastomosis. Preoperatively, $2(100 \%)$ patients had arterial hypertension and ascending aorta atherosclerosis. No other significant risk factors could be identified. One patient died due to intraoperative complete aortic rupture. In another case the dissected segment was replaced with a graft and proximal anastomoses were replanted in it under the hypothermic circulatory arrest. This patient required inotropic and respiratory support postoperatively. Mortality rate was $100 \%$, second patient died due to respiratory distress on $10^{\text {th }}$ postoperative day.

Conclusions: Intraoperative aortic dissection is an unpredictable and often fatal complication of cardiac surgery. Regarding to our data overall incidence of iatrogenic type A aortic dissections was $0,28 \%$. Increased age, high blood pressure and atheromatous disease of the ascending aorta could be significant risk factors for iatrogenic dissection in our series. Surgical interventions for iatrogenic aortic dissections require further improvement of surgical techniques and perioperative management.
\end{abstract}

Keywords: Iatrogenic aortic dissection, type A aortic dissection, ascending aortic aneurysm, acute aortic dissection. 


\section{Introduction and Background}

Intraoperative aortic dissection during cardiac surgery is infrequent, complicating surgical intervention in $0.04-1 \%$ of cases. Dissections can occur anywhere, most often as a result of direct mechanical damage at the location of the side clamp, site of cannulation of the aorta or at the site of proximal anastomosis and may manifest as hematoma, bleeding at the cannulation site or bleeding from the proximal anastomoses or aortic suture lines. Delayed diagnosis and treatment can lead to extremely high (23-41\%) mortality rate.

To prevent this complication, a number of authors recommend strict control of systolic blood pressure during the performing of proximal anastomoses; avoidance of aortic clamping with the use of total arterial revascularization or mechanical devices of a new generation to avoid any manipulations on aorta; and, in case of complications, aggressive replacement of the aorta with a prosthetic graft is positioned as a best approach. We conducted this study to identify current trends and risk factors for iatrogenic dissection.

\section{Patients and Methods}

A retrospective analysis of acute ascending aortic dissections complicating off-pump coronary artery bypass grafting surgery in 711 patients (mean age $54+/-2,3$ years old) in Republican Research Center of Emergency Medicine, from December 2013 to November 2017 was performed. Patients' data showed in Table 1.

Patients' preoperative risk factors, and operative and postoperative courses were analyzed.

\section{Results}

Of the 711 patients, who underwent off-pump coronary artery bypass, $2(0.28 \%)$ suffered iatrogenic intraoperative aortic dissection. In the first case a 68 -yearold man was scheduled for triple vessel off-pump bypass. After removal of the proximal partial clamp, the ascending aorta changed to a bluish color and bleeding from the site of proximal anastomosis was observed (Picture 1).
Despite of this, the surgery was continued in regular way and three venous grafts to the LAD, OM and RCA was performed. Surgical team made a mistake trying to resolve bleeding using wrapping the aorta. After the patient was transferred to ICU, the bleeding in the drainage tubes was observed, patient was urgently transferred to the operating room. The chest was reopened. After the opening of the chest, the events developed dramatically. There was a complete rupture of the aorta with massive bleeding and cardiac arrest. Despite of resuscitation procedures, patient died on the operating table.

In the second case a 62-year-old woman with triple vessel disease was prepared for elective surgery, three coronary arteries LAD, OM and RCA were planned to bypass on the beating heart. After removal of the proximal partial clamp, the type A aortic dissection was suspected, which was confirmed by epiaortic ultrasonography. Despite of this, the surgery was continued in regular way and three venous grafts to the LAD, $\mathrm{OM}$ and RCA was performed.

Surgical team made a mistake trying to resolve bleeding using wrapping the aorta. In early postoperative period, the malperfusion was observed and during computed tomography scan type A dissection of the aorta was diagnosed (Picture 2). Patient was urgently transferred into operating room and dissection was treated surgically.

Despite the inexperienced surgical team, the patient successfully underwent surgery and the simple tube graft ascending aorta replacement with the reimplantation of proximal anastomoses into the prosthesis under the hypothermic circulatory arrest was performed (Picture 3).

The postoperative period was complicated with respiratory failure as a result of massive transfusion, as well as violations of cognitive functions, on 8-9 postoperative day patient was physically and mentally in good condition. However, the patient died on the $10^{\text {th }}$ day after surgery as a result of respiratory distress syndrome. It is important to underline that both patients were in older age group (62 and 68 years old). In both cases patients had previous history of arterial hypertension and ascending aorta atherosclerosis. 


\section{Discussion}

Acute type A aortic dissection is a rare but extremely dramatic complication of elective cardiac surgery with a frequency of 0.04 to $1 \%{ }^{(1-4)}$ In our series, the incidence of this complication was $0.28 \%$. According to the literature, intraoperative dissections are observed more often ${ }^{(6,8)}$ although there are data on the dissections in early and late postoperative period ${ }^{(4)}$. The key factor for survival is on site diagnosis and early surgical correction of the complication, ${ }^{(5)}$ but some authors describe the long-term survival without surgery. ${ }^{(12)}$ In our series both cases of aortic dissection were observed intraoperatively, but the reaction of the surgical team, due to lack of experience, was belated, which probably also affected the outcome.

In most cases, as in our series, predisposing factors such as history of hypertension, ${ }^{(9)}$ atherosclerosis of the aorta, ascending aortic aneurysm, cystic medial necrosis or hereditary connective tissue disorders can be identified, as in spontaneous dissection of the aorta. Direct intimal trauma due to surgical aggression is the main trigger mechanism in combination with abnormal aortic conditions that are often present in the population undergoing the $\mathrm{CABG}$ operation. In most

Table 1. Patients' Characteristics

\begin{tabular}{|l|c|}
\hline Patients' data & $\%$ \\
\hline Male/female & $84 / 16$ \\
\hline Previous AMI & 73,3 \\
\hline DM & 67,8 \\
\hline Unstable angina & 94,4 \\
\hline Ongoing AMI & 5.6 \\
\hline Triple vessel & 75,3 \\
\hline LMS & 24,7 \\
\hline COPD & 36,3 \\
\hline EF & $46,6 \pm 4,3$ \\
\hline
\end{tabular}

cases place of manipulations such as aortic cannulation or proximal anastomoses site can be the starting point of dissection. ${ }^{(2,5)}$

Although OPCABG does not require cannulation and aortic cross-clamping, lateral clamp, can increase the risk of dissection due to the pulsating nature of blood pressure. According to some authors, uncontrolled arterial hypertension is the main subject of the onset of damage to the intima of the aorta. ${ }^{(5)}$ During conventional CABG using heart-lung machine, a temporary decrease of blood pressure, which is not pulsating, to a safe threshold $(50 \mathrm{~mm} \mathrm{Hg})$ is possible during the clamping of the aorta, facilitating placement of the clamp and a reduced probability of damage to the aortic clamp and its slipping. This important maneuver is not so easily realized during $\mathrm{OPCAB}$, and lateral clamping of the aorta can be dangerous when there are predisposing factors. During proximal anastomoses with pharmacological agents, the stress caused by a clamp on the aorta can be minimized.

At the same time, avoiding greater curvature of the aorta, the classic dissection site, for placing proximal anastomosis and preferring the inner part of the aorta, can reduce the risk of complications. In the presence of

Picture 1. IAAD was identified after removing the side clamp from the aorta in both patients, the intimal tear was located on the site of proximal anastomosis.

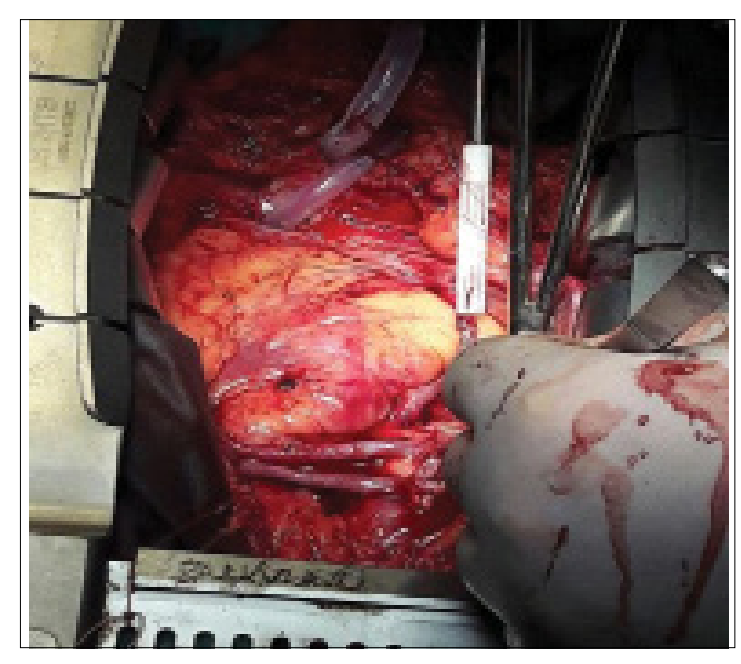


risk factors such as atherosclerosis of the aorta or its enlargement, it is recommended to minimize manipulation on the aorta. Total arterial revascularization using bilateral internal thoracic arteries and the gastroepiploic artery can be an ideal alternative method in such cases. ${ }^{(11)}$

The diagnosis of aortic dissection is a direct indication for immediate reconstruction, this complication diagnosed intraoperative often associated with a better prognosis, as it allows immediate repair of the prosthesis. ${ }^{(9)}$ In the postoperative period, the diagnosis can be suspected by the widened mediastinum, relapse of chest pain, peripheral ischemic changes, or more subtle visceral ischemic damage leading to a gradual increase in the ratio of lactic acid and urea to creatinine.

In our series, in first case the diagnosis of aortic dissection was suspected based on the postoperative data, whereas in the second case the intraoperatively diagnosed dissection was accompanied by signs of malperfusion in the postoperative period and was confirmed by $\mathrm{CT}$, but echocardiography was not performed in both cases. Transesophageal echocardiography allows to confirm the diagnosis, avoid delays in therapeutic treatment and directs the surgical strategy.

Early postoperative type A dissection usually requires a replacement of an ascending aorta. ${ }^{(9)}$ In the case of late type A dissection diagnosing, local repair was possible only in $2 \%$ of cases. ${ }^{(5)}$ Vein transplants can be attached using an "island flap" of the ascending aorta

Picture 2. CT scan of the patient with intraoperative acute type A aortic dissection.
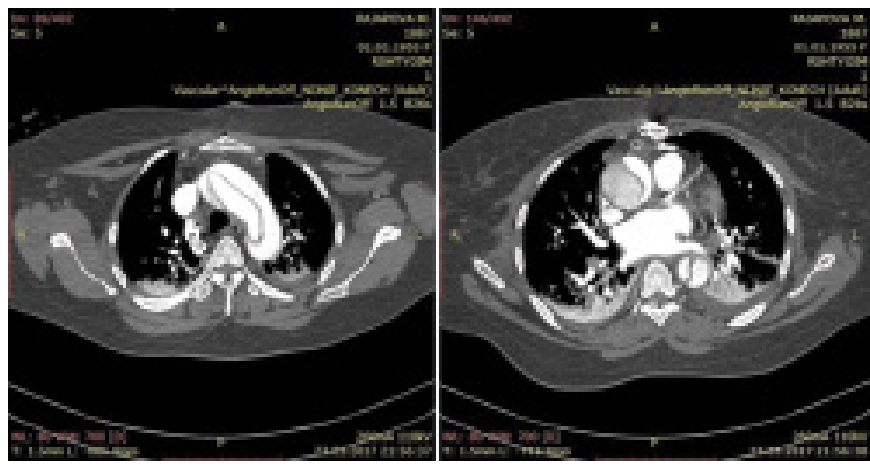

to the prosthesis or use a new subcutaneous vein, either inserted, or as a new shunt. ${ }^{(8)}$ Postoperative mortality ranges from $15 \%$ to $50 \% .^{(2,3,8)}$ In our series mortality rate achieved $100 \%$, one patient died intraoperatively due to acute aortic rupture, second patient died due to acute respiratory distress on $10^{\text {th }}$ postoperative day.

\section{Conclusions}

- Intraoperative aortic dissection is an unpredictable and often fatal complication of cardiac surgery. In this series incidence of type A aortic dissection was $0.28 \%$.

- Increased age, high blood pressure and atheromatous disease of the ascending aorta probably are significant risk factors for iatrogenic dissection.

- Surgical interventions for iatrogenic aortic dissections require further improvement of surgical techniques and perioperative management.

Picture 3. The dissected part of ascending aorta including all three proximal anastomoses was excised, the surrounding dissected layers of aortic wall were reattached using "sandwich" technique and first the distal anastomosis using open technique was performed, to avoid wrong lumen perfusion through the dissected right subclavian artery, the cardiopulmonary bypass was reestablished through the additional side graft on prosthesis. After the proximal anastomosis using the "sandwich" technique was done, all three venous grafts were then reattached to the Vascutek graft.

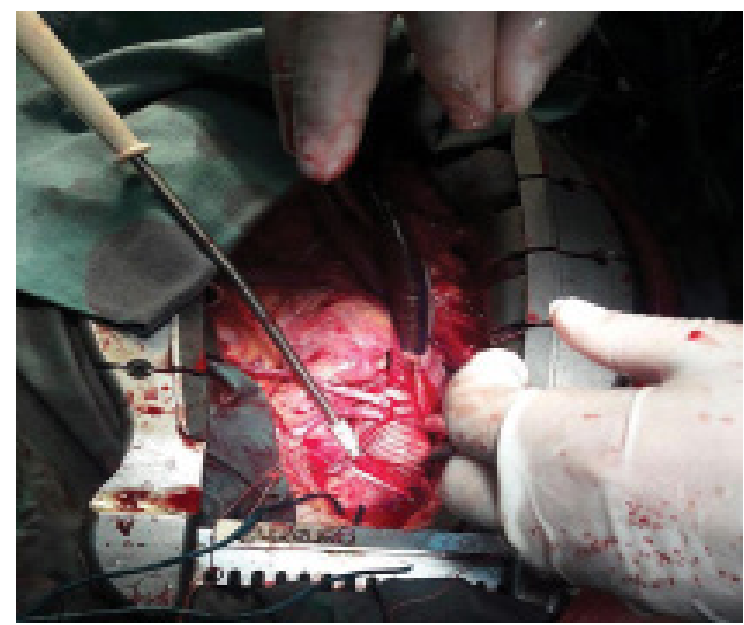




\section{References}

1. Still RJ, Hilgenberg AD, Akins CW, Daggett WM, Buckley MJ. Intraoperative aortic dissection. Ann Thorac Surg. 1992;53:374-9.

2. Hwang HY, Jeong DS, Kim KH, Kim KB, Ahn H. Iatrogenic type A aortic dissection during cardiac surgery. Interact Cardiovasc Thorac Surg. 2010;10:896-9.

3. Singh A., Mehta Y. Intraoperative aortic dissection. Ann Card Anaesth. 2015 Oct-Dec; 18(4): 537-542.

4. Leontyev S, Borger MA, Legare JF, Merk D, Hahn J, Seeburger J, Lehmann S. et al. Iatrogenic type A aortic dissection during cardiac procedures: early and late outcome in 48 patients. Eur J Cardiothorac Surg. 2012;41:641-646.

5. Chavanon O, Carrier M, Cartier R, Hébert Y, Pellerin M, Pagé P, Perrault LP. Increased incidence of acute ascending aortic dissection with off-pump aortocoronary bypass surgery? Ann Thorac Surg. 2001 Jan;71(1):117-21.

6. Dunning DW, Kahn JK, Hawkins ET, O’Neill WW. Iatrogenic coronary artery dissections extending into and involving the aortic root. Catheter Cardiovasc Interv. 2000;51:387-393.

7. Gomez-Moreno S, Sabate M, Jimenez-Quevedo P, Vazquez P, Alfonso

\section{Note}

Meeting presentation

The manuscript was presented (Poster) during $14^{\text {th }}$

International Congress of Update in Cardiology and

Cardiovascular surgery, Antalya, Turkey, 5-8 April 2018.
F, Angiolillo DJ, Hernandez-Antolin R. et al. Iatrogenic dissection of the ascending aorta following heart catheterisation: incidence, management and outcome. EuroIntervention. 2006;2:197-202.

8. Trimarchi S, Nienaber CA, Rampoldi V, Myrmel T, Suzuki T, Mehta $\mathrm{RH}$, Bossone E. et al. Contemporary results of surgery in acute type A aortic dissection: The International Registry of Acute Aortic Dissection experience. J Thorac Cardiovasc Surg. 2005;129: 1: 112-122

9. Hiratzka LF, Bakris GL, Beckman JA, Bersin RM, Carr VF, et al. (2010) ACCF/AHA/AATS/ACR/ASA/SCA/SCAI/SIR/STS/SVM guidelines for the diagnosis and management of patients with thoracic aortic disease. Circulation 121: e266-369.

10. Kobayashi J, Tagusari O, Bando K, Niwaya K, Nakajima H, Ishida M, Fukushima S, Kitamura S. Total arterial off-pump coronary revascularization with only internal thoracic artery and composite radial artery grafts. Heart Surg Forum. 2002;6(1):30-7.

11. Tam DY, Mazine A, Cheema AN, Yanagawa B. Conservative Management of Extensive Iatrogenic Aortic Dissection Aorta (Stamford). 2016 Dec; 4(6): 229-231.

12. Blakeman, B.M., Pifarre, R., Sullivan, H.J. et al. Perioperative dissection of the ascending aorta (types of repair) . J Card Surg. 1988; 3: 9-14
Received: $25 / 05 / 2018$

Accepted: 28/08/2018

Published: $15 / 09 / 2018$

Disclosure and conflicts of interest:

The authors declare no conflict of interest.

\section{Corresponding author:}

Abdusalom Abdulagzamovich Abdurakhmanov

Mail: babdurakhman@gmail.com 